\title{
Extralaryngeal division of the recurrent laryngeal nerve: A common and asymmetric anatomical variant
}

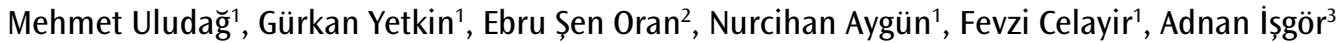

\section{ABSTRACT}

Cite this paper as:

Uludağ $M$, Yetkin $G$, Sen Oran E, Aygün N, Celayir F, Işgör A. Extralaryngeal division of the recurrent laryngeal nerve: a common and asymmetric anatomical variant. Turk J Surg 2017; 33: 164-168.

This study was presented at the XVI. Annual Meeting of the European Society of SurgeryESS, 22-24 November 2012, İstanbul, Turkey.

'Clinic of General Surgery, Ş̧̧̧̧̧i Hamidiye Etfal Training and Research Hospital, İstanbul, Turkey ${ }^{2}$ Clinic of General Surgery, Bakırköy Dr. Sadi Konuk Training and

Research Hospital, İstanbul, Turkey ${ }^{3}$ Department of General Surgery, Bahçeşehir University Schoo I of Medicine, İstanbul, Turkey

Address for Correspondence Mehmet Uludağ

e-mail:drmuludag@hotmail.com

Received: 06.08.2015

Accepted: 19.10.2015

○Copyright 2017

by Turkish Surgical Association
Objective: Recognition of extralaryngeal branching of the recurrent laryngeal nerve is crucial because prevention of vocal cord paralysis requires preservation of all branches of the recurrent laryngeal nerve. We assessed the prevalence of extralaryngeal branching of the recurrent laryngeal nerve and the median branching distance from the point of bifurcation to the entry point of the nerve into the larynx.

Material and Methods: Prospective operative data on recurrent laryngeal nerve branching were collected from 94 patients who underwent thyroid or parathyroid surgery between September 2011 and May 2012.

Results: A total of 161 recurrent laryngeal nerves were examined (82 right, 79 left). Overall, 77 (47.8\%) of 161 recurrent laryngeal nerves were bifurcated before entering the larynx. There were $36(43.9 \%)$ branching nerves on the right and $41(51.9 \%)$ branching nerves on the left, and there was no significant difference between the sides in terms of branching $(p=0.471)$. Among 67 patients who underwent bilateral exploration, $28.4 \%$ were found to have bilateral branching, $40.3 \%$ had unilateral branching, and the remaining $31.3 \%$ had no branching. The median branching distance was $15 \mathrm{~mm}(5-60 \mathrm{~mm})$.

Conclusion: Extralaryngeal division of recurrent laryngeal nerve is a common and asymmetric anatomical variant. These variations can be easily recognized if the recurrent laryngeal nerve is identified at the level of the inferior thyroid artery and then dissected totally to the entry point of the larynx. Inadvertent division of a branch may lead to vocal cord palsy postoperatively, even when the surgeon believes the integrity of the nerve has been preserved.

Keywords: Thyroid surgery, anatomic variations, recurrent laryngeal nerve, laryngeal branches, vocal cord palsy

\section{INTRODUCTION}

Thyroid surgery is a specific surgery that requires detailed anatomical information. The recurrent laryngeal nerve (RLN) is the major structure at risk during thyroid and parathyroid surgery (1). RLN paralysis is the most serious complication, along with postoperative hypocalcemia and hematoma, in thyroid surgery (2). Exploration and visual identification of the RLN is the gold standard method to preserve this nerve during thyroid surgery. Many factors have been reported to affect the development of RLN paralysis (2). One factor increasing the risk of RLN paralysis is anatomical variation of the RLN. Variations in the RLN can be produced by changes in the course of the nerve due to previous surgery or the impaction of a mass, the relationship between the RLN and inferior thyroid artery (ITA),the nonrecurrent laryngeal nerve course, and extralaryngeal branching $(3,4)$.

The relationship between the RLN and the ITA is variable. Makay et al. (5) defined 16 different relationships between the RLN and the ITA. Nonrecurrent laryngeal nerve course is a rare anatomic specialty. It is usually seen on the right side and arises during embryological development (6). Extralaryngeal branching of the RLN is a frequently seen anatomical specialty $(3,4)$. The risk of developing nerve paralysis is higher in extralaryngeal branching of the $\operatorname{RLN}(7,8)$. The nerve may be vulnerable to compression, traction, and transection due to the diminished caliber of the nerve due to the branching (9). A wide range of branching rates have been reported in studies on branching of the RLN (4). We aimed to assess the prevalence of RLN branching, the median branching distance, and the symmetry of the nerve.

\section{MATERIAL AND METHODS}

The collected prospective data of 94 patients, including 165 neck sides, who underwent thyroid or parathyroid surgery in two surgeons' practices focused on endocrine surgery (MU, Al) between September 2011 and May 2012 were evaluated in this study. Each side of the operated neck was considered as a separate entity. One side of each of the four bilaterally explorated patients with diagnoses of primary hyperthyroidism was excluded from the study because the nerve was not followed until the larynx entry point. One hundred and sixty-one RLNs that were followed along their courses until the larynx entry point were included in the study. 
This study was approved by the local ethics committee of our hospital. Written informed consent was obtained from all the patients.

\section{Surgical Technique}

While performing primary thyroidectomy and/or central neck dissection and bilateral parathyroid exploration, a 4-6 cm collar transverse incision was made. Superior and inferior subplatismal flaps were prepared, and the thyroid region was entered through the strap muscles. The area between the thyroid lobe and strap muscles was dissected, and the middle thyroid vein was taken.

After pulling the strap muscles laterally and the thyroid lobe anteromedially, the RLN was explored at the level of the medial section of the thyroid lobe where it crosses the ITA and followed until the laryngeal entry point under the cricopharyngeal muscle. The lateral approach was used for unilateral parathyroid exploration, revision thyroidectomy, and/or central neck dissection. After the dissection was performed through the anterior border of the sternocleidomastoid muscle and the lateral border of the strap muscles, the carotis sheath was found and the thyroid region was entered medially to the carotis artery. The RLN was explored and identified at the inferior section of the neck where it exits the thorax and was followed until the laryngeal nerve entry point (NEP) (10).

If the RLN had proximal branching before crossing the ITA, it was dissected until its branching point toward the inferior section in the medial approach. Therefore, the RLN was explored in the inferior section in the lateral approach, and the branchings proximally located to the ITA were already located in the dissection area; thus, there was no need for additional proximal dissection.

Any RLN branching was recorded. The distance between the point of bifurcation and the laryngeal NEP was measured in millimeters with a digital vernier caliper and defined as the branching distance. Only RLNs branching before entering the larynx at distances of $5 \mathrm{~mm}$ and greater were considered to be branched nerves; those branching in the last $5 \mathrm{~mm}$ were not categorized as branched because most RLNs branch in the last $5 \mathrm{~mm}$ before entering under the cricopharyngeal muscle $(11,12)$. Nerves with only posterior branches to the esophagus were not considered to be branching nerves. Nerves with two branches that both entered the larynx under the cricopharyngeal muscle were considered to be branching nerves $(13,14)$. It was found that some branching nerves bifurcated again from the anterior or posterior branches after the first bifurcation and entered the larynx as trifurcated nerves. This branching was defined as a secondary branching; details are provided in the results section.

At the end of each surgery, the demographic data of the patients, the indications for surgery, the surgical approach, and the anatomical data regarding the RLN were recorded in a Microsoft Excel table prepared at the beginning of the study.

\section{Statistical Analyses}

The data recorded in the Microsoft Excel table were used in the analyses. The descriptive statistics were given as number and percentage for categorical variables and mean value, standard deviation, and minimum and maximum values for numerical variables. The ratios of the categorical variables between the groups were analyzed by chi-square test. A value of $p<0.05$ was considered to be statistically significant.

\section{RESULTS}

The median age of the 94 patients ( 76 females, 18 males) enrolled in this study was 44years (range 18-90 years). The indications for surgery and the surgical procedures are summarized in Table 1, 2 respectively.

Branching was detected in 77 of the 161 RLNs (82 right, 79 left) evaluated in the study. Seventy-two (93.5\%) of 77 branching nerves had 2 branches, and the remaining 5 (6.5\%) had 3 branches as a result of secondary branching when entering the larynx. Branching was detected in 36 (43.9\%) of 82 nerves on the right side and 41 (51.9\%) of 79 nerves on the left side. There was no significant difference in the branching rates between the sides $(p=0.196)$. Three nerves on the right side (3.7\% of the nerves on the right side and $8.3 \%$ of the branching nerves) and two nerves on the left side ( $2.5 \%$ of the nerves on the left side and $4.9 \%$ of the branching nerves) were seen to enter the larynx as three branches as a result of secondary branching. The secondary branchings were found on the anterior branches in two nerves (one right, one left) and on the posterior branches in three nerves (two right, one left).

\begin{tabular}{|llc|}
\hline $\begin{array}{l}\text { Table 1. Indications for thyroid and/or parathyroid } \\
\text { operations }\end{array}$ \\
\hline Benign nodular goiter & MNG & 25 \\
& Recurrent goiter & 4 \\
& Solitary nodule & 5 \\
\hline Fine needle aspiration biopsy & Bethesda III-IV & 8 \\
& Bethesda V & 5 \\
& Bethesda VI & 7 \\
\hline Histopathologically & Hyperthyroidism & 3 \\
diagnosed malignancy & Toxic MNG & 8 \\
& Toxic adenoma & 4 \\
& Graves' disease & 7 \\
\hline Hyperparathyroidism & HPT & 14 \\
& HPT+ MNG & 2 \\
& HPT+ papillary thyroid cancer & 2 \\
\hline
\end{tabular}

MNG: multinodular goiter; HPT: hyperparathyroidism

Table 2. Surgical interventions performed

$\begin{array}{lll}\text { Bilateral exploration } & \text { TT } & 46 \\ & \text { TT+CLND } & 10 \\ & \text { TT+PT } & 3 \\ \text { BE+PT } & 7 \\ \text { Unilateral exploration } & \text { CLND } & 1 \\ & \text { PT } & 19 \\ & \text { PT+L } & 7\end{array}$

TT: total thyroidectomy; BE: bilateral exploration; CLND: central lymph node dissection; PT: parathyroidectomy; L: thyroid lobectomy 
Table 3. The branching properties of 161 nerves of 94 patients on the right and left sides

$\begin{array}{lll}\text { Bilateral exploration } & \text { Right branching+left non-branching } & 11 \\ & \text { Left branching+right non-branching } & 16 \\ & \text { Bilaterally branching } & 19 \\ & \text { Bilaterally non-branching } & 21 \\ \text { Unilateral exploration } & \text { Right side } & 6 \\ & \text { Branching } & 9 \\ & \text { Non-branching } & \\ & \text { Leftside } & 6 \\ & \text { Branching } & 6 \\ \text { Total } & \text { Non-branching } & 94\end{array}$

Table 4. The distribution of RLN branchings in patients who underwent bilateral intervention

\begin{tabular}{|lccc|}
\hline & $\begin{array}{c}\text { Right } \\
\text { branching }\end{array}$ & $\begin{array}{c}\text { Right } \\
\text { non-branching }\end{array}$ & Total \\
\hline Left branching & $19(28.4 \%)$ & $16(23.9 \%)$ & 35 \\
\hline Left non-branching & $11(16.4 \%)$ & $21(31.3 \%)$ & 32 \\
\hline Total & 30 & 37 & 67 \\
\hline
\end{tabular}

RLN: recurrent laryngeal nerve

19 (28.4\%), $27(40.3 \%)$, and 21 (31.4\%) of 67 bilaterally explored patients had bilateral, unilateral, and non-branching nerves, respectively (Table 3,4$)$. The mean branching distance was $15 \mathrm{~mm}$ (range 5-60 $\mathrm{mm}$ ).

If the right side was explored first in the bilaterally explored patients, the probability of detecting branching on the left side in the 30 patients with branched nerves was 63.6\% (19 patients); in the 37 patients with non-branched nerves, the probability was $43.2 \%$ (16 patients). No significant difference was determined when comparing the probabilities of branching on the left side with branching or non-branching RLNs on the right side $(p=0.082)$.

If the left side was explored first, the probability of detecting branching on the right side in the 35 patients with branched nerves was $54.3 \%$ (19 patients); in the 32 patients with nonbranched nerves, the probability was $34.4 \%$ (11 patients). No significant difference was determined when comparing the probabilities of branching on the right side with branching or non-branching RLNs on the left side $(p=0.082)$.

If branching was detected on the right or left side in the first exploration, no significant difference was determined when comparing the probabilities of identifying branching on the other side $(p=0.314)$. If a non-branched nerve was detected in the first side exploration (right or left), no significant difference was determined when comparing the probabilities of identifying branching on the other side $(p=0.307)$.

\section{DISCUSSION}

the subclavian artery on the right, curves up from the anterior to the posterior side of the aortic arch on the left, and enters the laryngeal entry point under the cricopharyngeal muscle. The right RLN enters the neck base more laterally than the left RLN because of its course around the right subclavian artery. Thus, the left RLN courses more strictly and closer to the trachea in the tracheoesophageal groove compared to the more oblique course in the paratracheal region on the right (15). The most important rule is that any tubular structure must not be divided unless the RLN is visually identified $(10,15)$. The RLN can be explored with three different approaches in the thyroid region: lateral, inferior, and superior (15). The lateral approach is the most commonly used approach for routine thyroidectomy. After traction of the strap muscles laterally and division of the middle thyroid vein, the thyroid lobe is retracted anteromedially at the midpolar level and the RLN is explored at the crossing point of the ITA and the RLN $(10,15)$. The RLN is found at the base of the neck in the inferior approach. The nerve is located more laterally on the right and in the paratracheal region on the left. The advantage of this approach, which is especially preferred for revision thyroidectomy, is that it allows the nerve to be explored in a loose areolar band atraumatically inferior to the previous surgical scar. In the superior approach, after the superior pole is dissected, the RLN is explored in the region of Berry's ligament where it enters the larynx. This approach can be used for large cervical and substernal goiters because this region is the most constant anatomic point for the RLN. Additionally, Berry's ligament is a fibrous structure and bleeds easily; thus, dissection is difficult in this area (15). Also, there may be branching in this area. It is important to remember that RLN injuries mostly occur close to Berry's ligament (4).

Extralaryngeal branching of the RLN is one of the most common anatomical variations $(3,4)$. Recognizing the branching and identifying all the branches of the RLN is an important factor in avoiding injury to the nerve. If a branched nerve is not detected, one of the identified branches can be considered as the main trunk. This situation may lead to inadvertent injury due to traction and division of the other branch (14). The most frequent cause of RLN paralysis is traction trauma. The power of traction due to traction of the thyroid lobe is reflected to the RLN in different proportions (16). Diminished diameter due to branching is an important risk factor for injury related to dissection and/or traction. The thinner nerve is more fragile and vulnerable to the maneuvers of routine dissection. The traction power over the branches is greatly diminished due to the decreased diameter and diminished coverage by tissues supporting the nerve, such as epineuria or fascia surrounding the nerve (9). The traction power upon the nerve is inversely proportional to the diameter of the nerve. The same traction causes greater tensile stress upon nerves with smaller diameters. The mean traction power that causes loss of the RLN signal detected by intraoperative neural monitoring can be calculated using the equation $\sigma=F / d^{2}(\sigma$ : traction power upon the nerve; F: traction force applied during the loss of signal; $\mathrm{d}$ : diameter of the RLN) (17). For example, when the diameter of the nerve decreases from $2 \mathrm{~mm}$ to $1 \mathrm{~mm}$, the same traction force applied to the $2 \mathrm{~mm}$ nerve reflects four fold on the $1 \mathrm{~mm}$ nerve. In other words, one fourth of a traction force that causes a loss of signal in the main trunk of a $2 \mathrm{~mm}$ nerve may cause a loss of signal in a branch of the same nerve that is $1 \mathrm{~mm}$ in diameter. Serpell et al. (18) reported that although the same traction force was applied to each nerve in their study, which included unilateral interventions, the rate of RLN paralysis 
on the left side was 2.7 times greater than that on the right side. They stated that a major factor was that the diameter of the nerve on the left $(1.6 \mathrm{~mm})$ was significantly thinner than that on the right $(1.7 \mathrm{~mm})(p=0.0012)$. Sancho et al. (8) found that the rate of vocal cord paralysis in branched nerves was two times greater thanthat in non-branched nerves $(15.8 \%$ vs $8.1 \%, p=0.022$ ). Also, the branching diameter was found to be significantly higher in paralyzed nerves than in functional nerves $(29.4+10.4 \mathrm{~mm}$ vs $19.1+9.8 \mathrm{~mm}, \mathrm{p}=0.003)$. Casella et al. (7) reported that the risk of RLN injury was 7 times greater for transient and 13 times greater for permanent unilateral paralysis in branched RLNs in comparison with non-branched RLNs after surgery. Branching of the RLN is reported in a wide range of $18.2 \%-72 \%$ in surgical series $(3,5,7-9,11-14,18-23)$. The rate is reported to increase $92.7 \%$ in autopsy studies (24). Extralaryngeal branching is often seen as bifurcation, and the rate of branching greater than bifurcation is reported to be $1.4 \%-7.3 \%$ in the literature $(3,20,23)$. The branching rate for more than two branches is $3.1 \%$, similar to the literature. Many factors have been reported in the literature to affect the branching rates provided in studies. These factors have been reported as gender, right side, extension of surgical exploration, use of magnifying loops, altering of the branching diameter due to the surgical position of the patient, use of intraoperative neuromonitoring, and some defined exclusion criteria $(3,4,7,9,12-14,21,25,26)$.

Serpell et al. (12) and Randolph (15) have stated that they observed some small branches of the RLN going to the trachea, esophagus, or inferior constrictor muscle in $50 \%-60 \%$ of patients; the rate of real extralaryngeal branches entering the larynx is $20 \%-30 \%$. The rates of extralaryngeal branching were reported as $64.5 \%$ and $72 \%$, respectively, in studies by Cernea et al. (3) and Ardito et al. (20) in which more than 2000 RLNs were evaluated. All the branches of the RLN entering the larynx were evaluated in these studies. Katz (11) reported the rate of extralaryngeal branching as $58 \%$ in his study, in which he accepted branches before the $5 \mathrm{~mm}$ distance to the NEP. In the past ten years, the branching rate has been reported as $24 \%$ $43 \%$ in studies in which branchings were accepted if the RLNs were branched $5 \mathrm{~mm}$ or more below the NEP $(12-14,21)$. We determined the branching rate to be $47.8 \%$, with $43.9 \%$ on the right and $51.9 \%$ on the left, in our study. It can be seen that although these rates are lower than those found by Katz (11), they are equal to or greater than the upper limit of the rates reported in recent studies. This high rate may be related to the surgical position of the patient. Kandil et al. (14) do not use a thyroid pillow to extend the neck; they reported branching distances of $7.5 \mathrm{~mm}$ on the right and $8.3 \mathrm{~mm}$ on the left. The median branching distance is $15 \mathrm{~mm}$ in our study, which is higher than these values. This high value may be related to our use of a thyroid pillow to extend the neck, leading to nerve stretching due to the position. The branchings within $5 \mathrm{~mm}$ that were not evaluated as real branchings in the study by Kandil et al. $(13,14)$ may have been evaluated as branching due to neck extension in our study. There is no data regarding the position of the patient in other studies. The gender and posture of the body also may affect the length of the nerve (13).

In our study, we detected bilateral branching in $28.4 \%$, unilateral branching in $40.3 \%$, and no branching in $31.4 \%$ of the bilaterally explored patients. This rate of bilateral branching is similar to the rate of $8.9 \%-33.3 \%$ that is reported in the literature $(12,13,19,22)$. In our study, if branching was observed in a patient, this branching was unilateral and asymmetric on the right or left at a rate of 58.9\%. Gürleyik (19) reported the rate of unilateral branching as $71.4 \%$ in his study including $292 \mathrm{RLNs}$, in which the general branching rate was $31 \%$. In their study, Serpell et al. (12) reported a rate of bilateral branching of $8.9 \%$ and a rate of unilateral branching of $77.9 \%$ in patients who underwent bilateral intervention. Serpell et al. (12) expressed that they always started from the left side while performing bilateral thyroidectomy. They found that when a branching nerve was detected on the left, the probability of finding a branching nerve on the right was $42.6 \%$, and when a non-branching nerve was detected on the left, the probability of finding a branching nerve on the right was $24.3 \%$. They reported that when a branching nerve was found on the left, the probability of finding a branching nerve on the other side was significantly high. Our preference is to start from the side with the pathological lesion when performing bilateral thyroidectomy. According to our data, when we started from the right and a branching nerve was found, the probability of finding a branching nerve on the left was 63.3\%; however, if we started from the left and a branching nerve was found, the probability of finding a branching nerve on the right was $54.4 \%$. If a non-branching nerve was found on the right, the probability of finding a branching nerve on the left was $43.2 \%$, and if a non-branching nerve was found when starting from the left side, the probability of finding a branching nerve on the right was $34.4 \%$. No significant difference was determined in terms of finding a branched nerve on the opposite side according to whether a branching or non-branching nerve was found on the first side explored. Also, the probabilities of finding a branching nerve on the opposite side were similar when branching and non-branching nerves were found on the first side (right or left). According to our data, when branching was present on the first side in bilaterally explored patients, a branching nerve was found on the opposite side in at least half the patients; if a non-branching nerve was found on the first side, branching was found on the opposite side in at least in one third of the patients. This is an important anatomical detail that should be considered in order to protect the RLN.

It is reported in some studies that branching is more frequent on the right side than on the left side $(8,21)$. Beneragama and Serpell (21) defined that the anatomic course of the RLN is different on the right and left, and the relationship with the ITA is more variable on the right. They stated that this embryological difference may be related to the increased frequency of RLN branching on the right. They found similar rates between the right and left sides in their subsequent extensive studies and stated that the observations obtained from more extensive series may be more reliable (12). The branching rates were found to be similar between the right and left sides in other studies $(9,13,14,18)$.

In some studies, it is suggested that the RLN should be explored on its last part around Berry's ligament before entering the larynx, and it is stated that early identification of RLN will not prevent its injury (25). The mean branching distance is reported as 6-19 $\mathrm{mm}$ in the literature $(7-9,12,14)$. Gürleyik (19) divided the branchings into four classes on the basis of the points where they cross the ITA: $37.5 \%$ arterial, $32.5 \%$ postarterial, $15 \%$ prelaryngeal, and $15 \%$ prearterial. The median branching distance is $15 \mathrm{~mm}$ in our study, and the branching point is in the last $2-2.5 \mathrm{~cm}$ of the RLN where it crosses the ITA before entering the larynx. Partial exploration of the RLN 
around Berry's ligament may cause many proximal branchings to be overlooked. Most branchings can be easily recognized by exploration of the RLN at the level of the ITA (4).

\section{CONCLUSION}

It is impossible to predict the branchings and other variations of the RLN preoperatively. The probability of branching of the RLN is high, and the branching is usually asymmetrical, with a unilateral rate of $60 \%$ in bilateral surgical approaches. When branching is present on the first explored side in bilaterally explored patients, branching is found on the opposite side in at least half of all cases; however, if there is no branching on the first side, branching is found on the opposite side in at least one third of all cases.Therefore, branching is an anatomical detail that should always be considered in the exploration of both sides. All the branches of the RLN must be set out to reduce the risk of injury, especially in the branching nerves, and save all the branches. The RLN must be explored in the region where it crosses the ITA, and all the branches must be followed until the nerve enters the larynx to mark all the branches clearly and save them. The injury of a nerve branch may unwittingly lead to vocal cord paralysis, although the surgeon may believe that the nerve was protected.

Ethics Committee Approval: Ethics committee approval was received for this study from the ethics committee of Şişli Etfal Training and Research Hospital.

Informed Consent: Written informed consent was obtained from patients who participated in this study.

Peer-review: Externally peer-reviewed.

Author Contributions: Concept - M.U., A.I.; Design - M.U., G.Y.; Supervision - M.U., G.Y.; Resource - M.U.; Materials - M.U., G.Y.; Data Collection and/or Processing - E.Ş.O., N.A., .FC.; Analysis and/or Interpretation M.U., A.I. ; Literature Search - M.U., N.A.; Writing Manuscript - M.U.; Critical Reviews - A.I.

Conflict of Interest: No conflict of interest was declared by the authors.

Financial Disclosure: The authors declared that this study has received no financial support.

\section{REFERENCES}

1. Gremillion G, Fatakia A, Dornelles A, Amedee RG. Intraoperative recurrent laryngeal nerve monitoring in thyroid surgery: Is it worth the cost? The Ochsner J 2012;12: 363-366.

2. Dralle H, Sekulla C, Haerting J, Timmermann W, Neumann HJ, Kruse $E$, et al. Risk factors of paralysis and functional outcome after recurrent laryngeal nerve monitoring in thyroid surgery. Surgery 2004; 136: 1310-1322. [CrossRef]

3. Cernea CR, Hojaij FC, De Carlucci D Jr, Gotoda R, Plopper C, Vanderlei $F$, et al. Recurrent laryngeal nerve: a plexus rather than a nerve? Arch Otolaryngol Head Neck Surg 2009; 135: 1098-1102. [CrossRef]

4. Chiang FY, Lu IC, Chen HC, Chen HY, Tsai CJ, Hsiao PJ, et al. Anatomical variations of recurrent laryngeal nerve during thyroid surgery: how to identify and handle the variations with intraoperative neuromonitoring. Kaohsiung J Med Sci 2010; 26: 575-583. [CrossRef]

5. Makay O, Icoz G, Yilmaz M, Akyildiz M, Yetkin E. The recurrent laryngeal nerve and the inferior thyroid artery-anatomical variations during surgery. Langenbecks Arch Surg 2008; 393: 681-685. [CrossRef]

6. Uludag M, Isgor A, Yetgin G, Citgez B. Anatomic variations of the non-recurrent inferior laryngeal nerve. BMJ Case Rep 2009; pii: bcr10.2008.1107.
7. Casella C, Pata G, Nascimbeni R, Mittempergher F, Salerni B. Does extralaryngeal branching have an impact on the rate of postoperative transient or permanent recurrent laryngeal nerve palsy? World J Surg 2009; 33: 261-265. [CrossRef]

8. Sancho JJ, Pascual-Damieta M, Pereira JA, Carrera MJ, Fontané J, Sitges-Serra A. Risk factors for transient vocal cord palsy after thyroidectomy. Br J Surg 2008; 95: 961-967. [CrossRef]

9. Fontenot TE, Randolph GW, Friedlander PL, Masoodi H, Yola IM, Kandil E. Gender, race, and electrophysiologic characteristics of the branched recurrent laryngeal nerve. Laryngoscope 2014; 124: 2433-2437. [CrossRef]

10. Uludağ $M$, İşgör $A$. Geleneksel tiroidektomi yöntemleri ve teknik ayrıntılar. İşgör $A$, Uludağ $M$, editörler. Tiroit. 1. Baskı. Nobel Tıp Kitabevleri; 2013. p.817-54.

11. Katz AD. Extralaryngeal division of the recurrent laryngeal nerve. Report on 400 patients and the 721 nerves measured. Am J Surg 1986; 152: 407-410. [CrossRef]

12. Serpell JW, Yeung MJ, Grodski S. The motor fibers of the recurrent laryngeal nerve are located in the anterior extralaryngeal branch. Ann Surg 2009; 249: 648-652. [CrossRef]

13. Kandil E, Abdel Khalek M, Aslam R, Friedlander P, Bellows CF, Slakey $D$. Recurrent laryngeal nerve: significance of the anterior extralaryngeal branch. Surgery 2011; 149: 820-824. [CrossRef]

14. Kandil E, Abdelghani S, Friedlander P, Alrasheedi S, Tufano RP, Bellows $\mathrm{CF}$, et al. Motor and sensory branching of the recurrent laryngeal nerve in thyroid surgery. Surgery 2011;150: 1222-1227. [CrossRef]

15. Randolph GW. Surgical anatomy and monitoring of the recurrent laryngeal nerve. In: Randolph GW, editor. Surgery of the Thyroid and Parathyroid Glands. 2nd ed. Elsevier Saunders; 2013. p. 306340

16. Chiang FY, Lu IC, Kuo WR, Lee KW, Chang NC, Wu CW. The mechanism of recurrent laryngeal nerve injury during thyroid surgerythe application of intraoperative neuromonitoring. Surgery 2008; 143: 743-749. [CrossRef]

17. Lee HY, Cho YG, You JY, Choi BH, Kim JY, Wu CW, et al. Traction injury of the recurrent laryngeal nerve: Results of continuous intraoperative neuromonitoring in a swine model. Head Neck 2016; 38: 582-588. [CrossRef]

18. Serpell JW, Lee JC, Yeung MJ, Grodski S, Johnson W, Bailey M. Differential recurrent laryngeal nerve palsy rates after thyroidectomy. Surgery 2014; 156: 1157-1166. [CrossRef]

19. Gurleyik E. Location of motor fibers within branches of the recurrent laryngeal nerve with extralaryngeal terminal bifurcation; Functional identification by intraoperative neuromonitoring. Surgery 2015; 158: 1339-1344. [CrossRef]

20. Ardito G, Revelli L, D'Alatri L, Lerro V, Guidi ML, Ardito F.Revisited anatomy of the recurrent laryngeal nerves. Am J Surg 2004; 187: 249-253. [CrossRef]

21. Beneragama T, Serpell JW. Extralaryngeal bifurcation of the recurrent laryngeal nerve: a common variation. ANZ J Surg 2006; 76: 928-931. [CrossRef]

22. Gurleyik E. Surgical anatomy of bilateral extralaryngeal bifurcation of the recurrent laryngeal nerve: similarities and differences between both sides. N Am J Med Sci 2014; 6: 445-449. [CrossRef]

23. Gregg RL. Avoiding injury to the extralaryngeal nerves. Ann Otol Rhinol Laryngol 1957; 66: 656-678. [CrossRef]

24. Yalçin B, Tuğcu H, Cantürk N, Ozan H. Laryngeal branching pattern of the inferior laryngeal nerve, before entering the larynx. Surg Radiol Anat 2006; 28: 339-342. [CrossRef]

25. Reeve T, Thompson NW. Complications of thyroid surgery: how to avoid them, how to manage them, and observations on their possible effect on the whole patient. World J Surg 2000; 24: 971975. [CrossRef]

26. Barczyński M, Konturek A, Stopa M, Hubalewska-Dydejczyk A, Richter $\mathrm{P}$, Nowak W. Clinical value of intraoperative neuromonitoring of the recurrent laryngeal nerves in improving outcomes of surgery for well-differentiated thyroid cancer. Pol Przegl Chir 2011; 83: 196-203. [CrossRef] 